\title{
Incorporación de reuniones Briefing como herramienta de mejora de la comunicación interprofesional en la unidad de trasplante
} renal

\author{
Trinidad López Sánchez, Marta Pérez Doctor, Jesús Zambrana Hervás, Mª Luz Amoedo Cabrera, Ma \\ Carmen Chozas López
}

\section{Hospital Universitario Virgen Del Rocío. Sevilla}

\section{Introducción:}

Los problemas de comunicación son un factor causal común en la producción de eventos adversos asistenciales con abundancia de errores derivados de la transmisión de información interprofesional constituyendo un factor de variabilidad en la práctica clínica que puede derivar en unos resultados asistenciales que ponen en riesgo la seguridad del paciente. Los briefings son reuniones informativas interdisciplinares donde se discuten riesgos potenciales para los pacientes o eventos adversos ocurridos en la práctica diaria.

\section{Objetivos:}

- General: Fomentar la cultura de seguridad del paciente entre los profesionales encargados de gestionar los cuidados del paciente renal trasplantado (PRT).

- Específico: Iniciar un programa de reuniones interdisciplinares "briefing" en la unidad de trasplante renal.

\section{Metodología:}

- Formación profesional básica en gestión de riesgos: talleres básicos para la implantación de prácticas seguras a través del Observatorio para la Seguridad del Paciente.

- Reuniones de los profesionales para:

- Identificación concreta y puesta en común (evidencia interna) de las causas de eventos adversos en el cuidado al PRT en relación a los elementos clave de revisión con definición previa del perfil de estos pacientes.

- Registro de estas experiencias en los planes de acogida a los profesionales de nueva incorporación.

- Definición y consenso en la notificación de eventos adversos (según protocolo del centro) y propuestas de abordaje como la cumplimentación del "Cuestionario de autoevaluación de la seguridad del sistema de utilización de medicamentos en hospitales."

\section{Resultados:}

1. Edición de una sesión clínica bibliográfica y exposición de contenidos sobre implantación de prácticas seguras.

2. Edición del cronograma de reuniones periódicas briefing: cortas, interdisciplinares y con horario asequible a los turnos de trabajo en las que se revisan los riesgos identificados derivados de:

- infección nosocomial y sobreinfecciones: protocolos de asepsia, medidas de aislamiento y protección, recomendaciones al alta.

- complicaciones perioperatorias relacionadas con: preparación a quirófano y recepción del paciente trasplantado desde la UCI (check-list prequirúrgico y de acogida), información al paciente/familiares y receptor reserva. 
- Errores en el uso de la medicación: prescripciones, etiquetado, envasado/nombre, almacenamiento, estandarización, dispositivos y distribución. Atención a posología y efectos de inmunosupresores, antineoplásicos, inmunoglobulinas, etc.

- Cuidados de enfermería: ejecución de actividades según protocolos y procedimientos estandarizados y actualizados y focalización en las intervenciones NIC independientes y las que detectan precozmente complicaciones: fiebre, fuga urinaria, edema agudo de pulmón, estreñimiento, desequilibrio de líquidos, hipo/hipertensión.

- Comunicación: información sobre pacientes, traslados, cumplimentación de registros específicos, cambios de turno y evoluciones integrales y ordenadas.

- Otras: identificación de los pacientes, riesgo de caídas, factores del entorno (mobiliario, limpieza ), competencia y formación profesional (mapa de competencias de nefrología y diálisis).

\section{Conclusiones:}

Las reuniones briefing ayudan a concienciar a los profesionales sobre la seguridad del paciente, incrementar la alerta en el desarrollo profesional sin temor a represalias y aumentar las notificaciones de eventos adversos para implantar acciones de mejora de la calidad asistencial.

\section{Referencias Bibliográficas}

1. Estrategias de mejora para la seguridad del paciente: briefing. Observatorio para la Seguridad del Paciente. Agencia de Calidad Sanitaria de Andalucía.

2. Guía de diseño y mejora continua de procesos asistenciales. Plan de Calidad: Nuevas estrategias para la sanidad andaluza. Consejería de Salud.

3. Manual de Competencias específicas de enfermeros en Atención hospitalaria: hospitalización y cuidados especiales. Agencia de Calidad Sanitaria. Consejería de Salud.

4. Tratamiento sustitutivo de la insuficiencia renal crónica proceso asistencial integrado (Sevilla) Consejería de Salud (2005). 